\author{
اقتصاديات محصول الأرة الثامية وفقا لنظم الري بمحافظة الثرقية

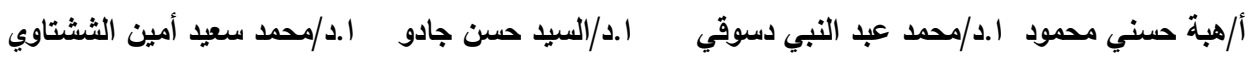 \\ كلية الزراعة بمشتهر قسم الاقتصاد الزراعي \\ معهد بحوث الاقتصاد الزراعي

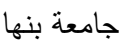

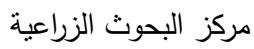

heba.hosney@hotmail.com

الملذص باللغة العربية

الذرة الثامية أحد أهم محاصيل الحبوب الرئيسية والهامة في مصر ، نظرا لتعدد مجالات استخدامه سواء كان الغذاء البشري (الانسان)

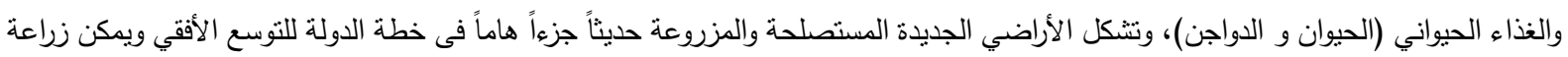

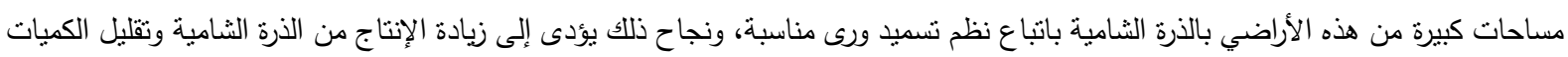

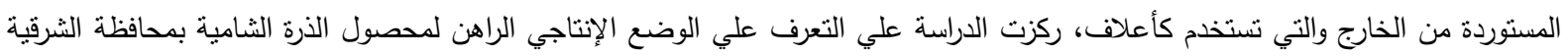

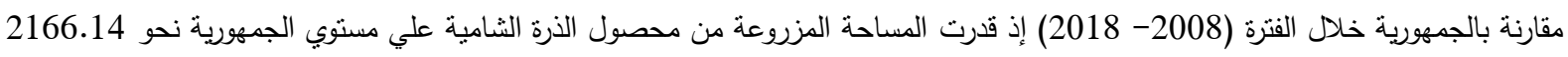

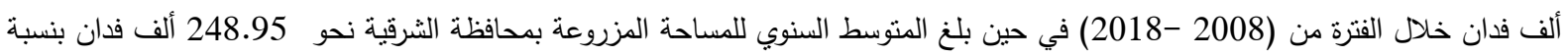

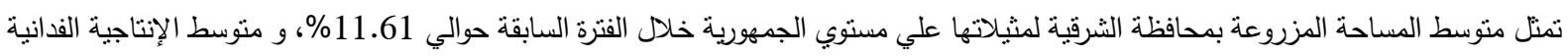
بلغ 3.25 طن/فدان، 3.34 طن/فدان علي مستوي الجمهورية، ومحافظة الثرقية علي الترتيب.أما بالنسبة للإنتاج الكلي لمحصول الذرة الثامية فقد بلغ متوسط الانتاج 6908.53 ألف طن، 852.07 ألف طن علي مستوي الجمهورية، ومحافظة الثرقية علي التزتيب.، ويمثل منوسط الإنتاج

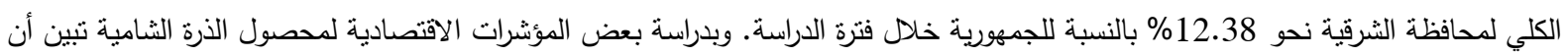

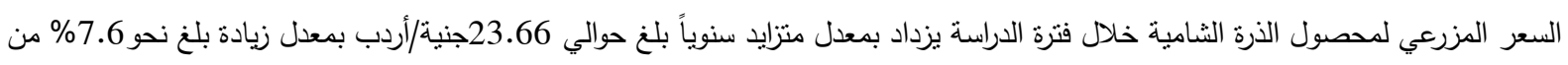
متوسط السعر المزرعي للمحصول والتي بلغت حوالي 309.45 خلال فتزرة الدراسة ،في حين تزداد التكاليف الكلية بمعدل متزايد سنويا بنحو 388.78جنية/فدان بمعدل زيادة بلغ نحو 10.97\% من متوسط التكاليف الكلية والتي قدرت بنحو 3544.45 35نية/فدان خلال فترة الدراسة، بينما

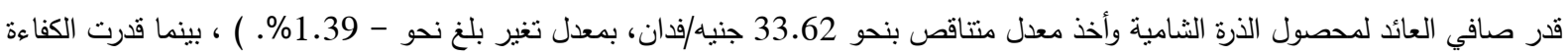

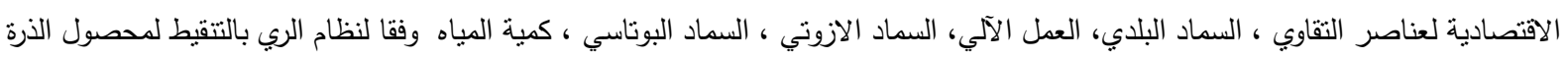

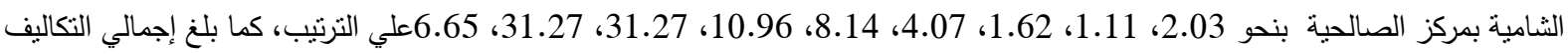

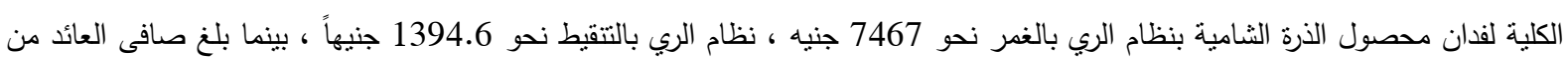

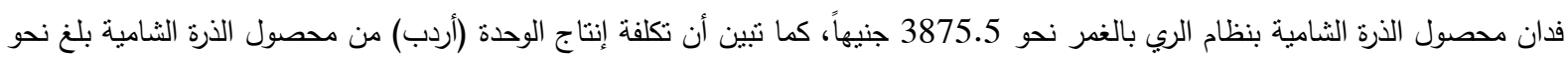

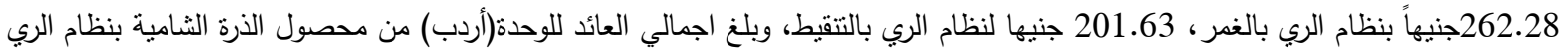

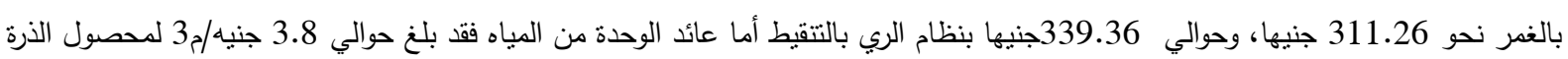

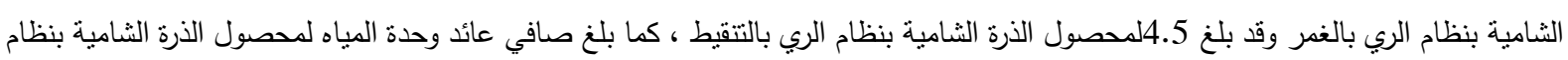
الري بالغمر نحو 0.6 جنيها/م3 بينما بلغ نحو 1.8 جنيها/33 لدحصول الذرة الثنامية بنظام الري بالتتقيط ، أما عن تكلفة وحدة المياه للتكاليف

الكلية فقد بلغت 3.2جنيها/33، وبلغت حوالي 2.6 جنيها/23 بالنسبة لمحصول الذرة الثامية بنظام الري بالغعر ، الري بالتقيط علي الترتيب.

توصيات الدراسة:

التوسع في استخدام نظم الري الحديثة عند زارعة محصول الذرة الثامية في الأراضي الجديدة لأنها نحقق عائد أعلي للمزارع وتوفر في

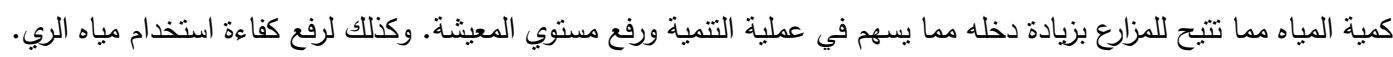
تطبيق نظم الري الديثة في المناطق حديثة الاستصلاح والأراضي الجديدة وتطوير الريا. تفعيل دور الارشاد الزراعي لتوعية المزارعين لنترشيد استخدام مياه الري. 
مقدمة:

يعد محصول الذرة الثامية أحد محاصيل الحبوب الرئيسية والهامة في مصر ، نظرا لتعدد مجالات استخدامه سواء كان الغذاء البشري (الانسان)

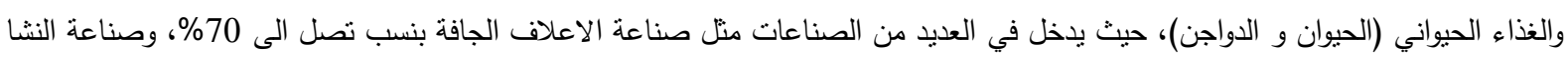
وزيت الذرة والفركتوز والدكسترين و سكر الجلوكوز ، وأما بالنسبة للحيوانات والدواجن فهو احد المكونات الهامة فى علأئقها ، وتهن ، وتحتوي المائة جرام

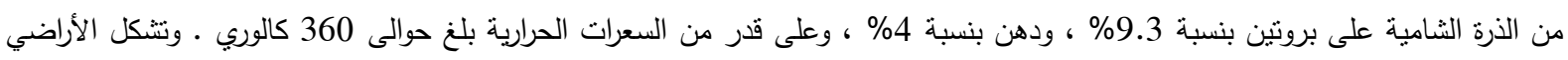

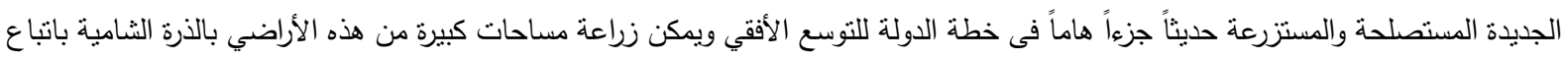

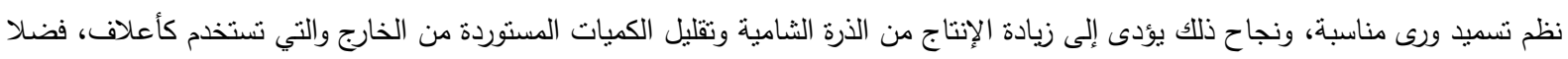
عن زيادة الإنتاجية الفدائية عن طريق التوسع فى زراعة الهجن عاجية عالية الإنتاجية. وتبلغ المساحة المزروعة بمحصول الذرة الثامية فى مصر حوالي فئي

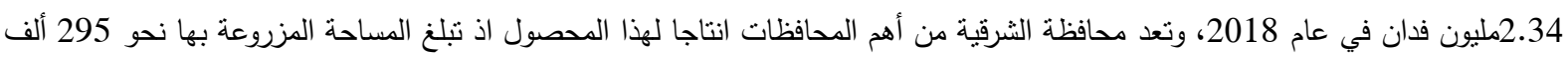

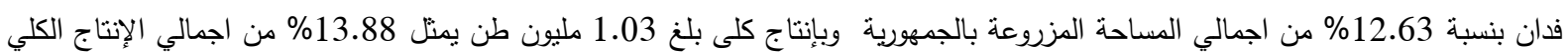

بالجمهورية.

مشكلة الدراسة: نظرا لأهمية محصول الذرة الثامية في مصر كأحد محاصيل الحبوب الهامة في مصر ، فان الامر يتطلب دراسة هذا المحصول والتعرف على الوضع الراهن للمساحة و الإنتاج والإنتاجية ، وتكمن مشكلة البحث فى تزايد أهمية الذرة الثامية في ظل تزايد الفجوة الغذائية منه والرغبة في تنمية الثروة الحيوانية التي تعتمد إلي حد كبير علي الأعلاف المصنعة من الذرة في ظل كميات المباه المتاحة بالإضافة إلي تحقيق الاستخدام الأمثل للموارد الزراعية وخاصة المورد المائي.

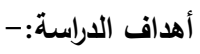
يستهدف هذا البحث القاء الضوء على :

1-تطور المؤشرات الإنتاجية والاقتصادية لمحصول الذرة الثامية فى مصر ومحافظة الثرقية.

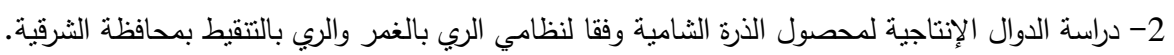
3- الكفاءة الاقتصادية لمحصول الذرة الثامية وفقا لنظم الري بعينة الدراسة.

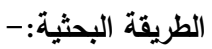

اعتمدت الدراسة فى أسلوبها البحثى على اتباع المنهج الاستقرائى فى التحليل الاقتصادي من الناحية الوصفية ، اتباع المنهج الاستتباطى من

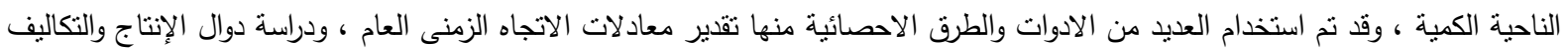

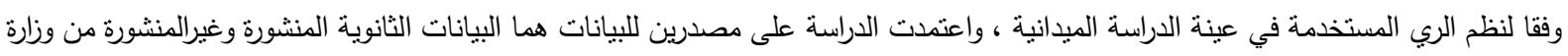

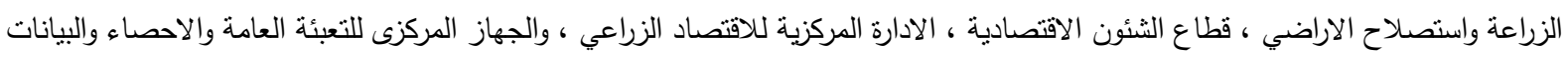

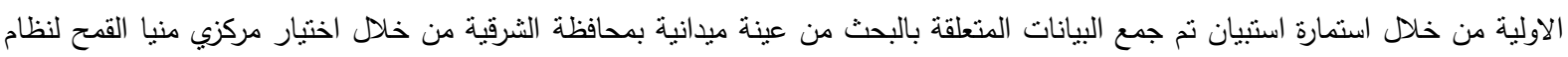

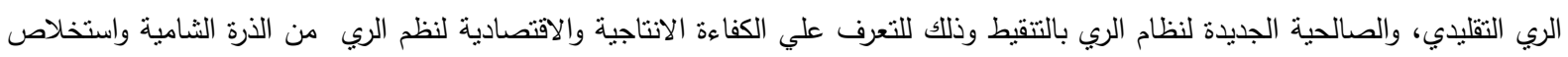

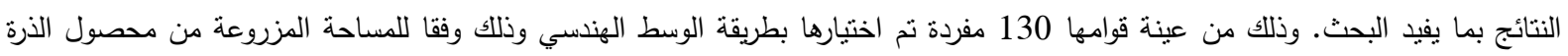

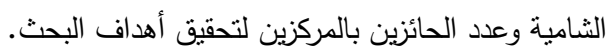

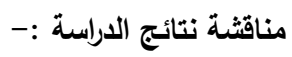

أولا: الوضع الإنتاجي الحالي لمحصول الذرة الثامية بمحافظة الثرقية مقارنة بالجمهورية: يوضح الجدول (1) أن متوسط المساحة المزروعة من محصول الذرة الثامية علي مستوي الجمهورية بلغ 2166.14 ألف فدان خلا لإلف

الفترة من (2008 -2018) في حين بلغ المتوسط السنوي للمساحة المزروعة بمحافظة الثرقية نحو 248.95 ألف فدان بنسبة قدرت بنحو 61.61\% من الجمهورية، ويتضح من ذات الجدول أن منوسط الإنتاجية الفدانية خلال فترة الدراسة علي مستوي الجمهورية بلغ 3.25 طن/فدان وبالنسبة لمحافظة الثرقية قدرت بنحو 3.34 طن/فدان. وقد قدر متوسط الانتاج الكلي لمحصول الذرة الثامية بحوالي 6908.53 ألف طن، 852.07 ألف طن على مستوي الجمهورية ومحافظة الثرقية وبنسبة قدرت بنحو 12.38\% من انتاج الجمهورية خلال فترة الدراسة.

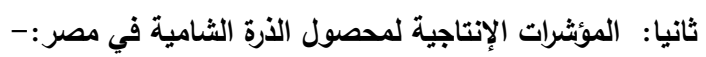
1-المساحة المزروعة بمحصول الذرة الثامية في مصر: 
تثثير نتائج الجدول (2)، أن متوسط المساحة المزروعة بمحصول الذرة الثامية الصيفي قد بلغ 2166.14 ألف فدان خلال الفترة (20182008)، وأن هذه السساحة كانت تتذبذب انخفاضاً وارتفاعاً، حيث بلغ حدها الأدنى حوالي 1758ألف فدان عام 2011 بنقص قدر بنحو عن سنة الاساس عام 2008، وبلغ حدها الأقصى حوالى 2614 ألف فدان عام 2015، بزيادة قدرت بحوالى 140.54\% عن سنة الأساس.

جدول رقم 1. الأهمية النسبية للمساحة والانتاجية والإنتاج الكلي من محصول الذرة الثامية بمحافظة الثرقية والجمهورية خلال الفترة (2008 $(2018$

\begin{tabular}{|c|c|c|c|c|c|c|c|c|}
\hline \multirow[b]{2}{*}{$\%$} & \multicolumn{2}{|c|}{ الإنتاج (الألف طن) } & \multicolumn{2}{|c|}{ الإنتاجية(طن) } & \multicolumn{3}{|c|}{ المساحة (الألف فدان) } & \multirow{2}{*}{ السنوات ل } \\
\hline & شرقية & جمهورية & شرقية & جمهورية & $\%$ & شرقية & جمهورية & \\
\hline 10.62 & 670 & 6306.052 & 3.32 & 3.28 & 10.86 & 202 & 1860 & 2008 \\
\hline 11.51 & 765 & 6644.4 & 3.06 & 3.36 & 11.83 & 234 & 1977.6 & 2009 \\
\hline 16.36 & 1027 & 6275.8 & 3.28 & 3.14 & 15.67 & 313.1 & 1998 & 2010 \\
\hline 13.80 & 812 & 5885.7 & 3.37 & 3.35 & 13.70 & 240.9 & 1758 & 2011 \\
\hline 11.98 & 863 & 7205.5 & 3.40 & 3.34 & 11.68 & 252 & 2157 & 2012 \\
\hline 12.70 & 902 & 7101.9 & 3.50 & 3.32 & 11.95 & 255.6 & 2139 & 2013 \\
\hline 11.98 & 868 & 7248.2 & 3.50 & 3.32 & 10.02 & 247.8 & 2474 & 2014 \\
\hline 11.96 & 844 & 7057.7 & 3.32 & 3.12 & 9.72 & 254 & 2614 & 2015 \\
\hline 10.62 & 762 & 7177.3 & 3.30 & 3.18 & 9.89 & 219 & 2214.66 & 2016 \\
\hline 10.82 & 829 & 7662.6 & 3.40 & 3.27 & 9.78 & 225 & 2299.7 & 2017 \\
\hline 13.88 & 1030.8 & 7428.7 & 3.30 & 3.05 & 12.63 & 295 & 2335.6 & 2018 \\
\hline 12.38 & 852.07 & 6908.53 & 3.34 & 3.25 & 11.61 & 248.95 & 2166.14 & المنوسط \\
\hline
\end{tabular}

المصدر: جمعت وحسبت من وزارة الزراعة واستصلاح الأراضي- قطاع الثئون الاقتصادية، نشرات الاقتصاد الزراعي، أعداد مختلفة.

2-2 الانتاجية الفدانية لمصصول الذرة الثامية في مصر تثتير بيانات الجدول (2)، أن الانتاجية الفدانية من محصول الذرة الثامية الصيفي خلال الفترة (2018/2008) بلغ متوسطها

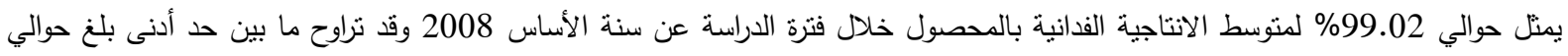
3.05طن/فدان عام 2018، وحد أقصى بلغ حوالي 3.36 طن/فدان عام 2009، أي بزيادة قدرها نحو 102.44 \% من سنه الأساس.

\section{3-الإنتاج الكلى لمحصول الذرة الثامية في مصر:}

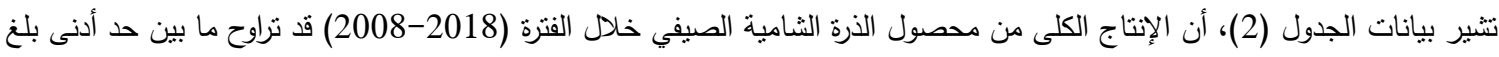
حوالي 5.88 مليون طن عام 2011، وحد أقصى بلغ حوالي 7.66 مليون طن عام 2017، ويعكس ذلك زيادة الإنتاج الكلى بمقار 121.39 121. عن سنة الأساس، وحوالي 109.32\% عن منوسط الإنتاج الكلى خلال فترة الدراسة والمقدر بحوالي 6.89 مليون طن.

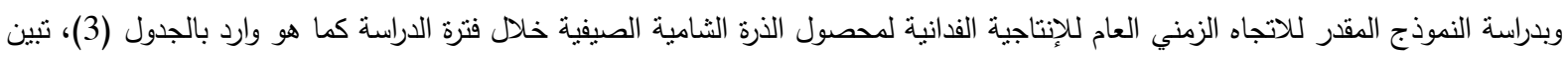
أنها تتقص سنوياً بمقادير غير مؤكدة إحصائياً بلغت حوالى16.24 طن، أي أن التغيرات في الإنتاجية الفدانية لمحصول الذرة الثنامية تدور حول 
جدول رقم2. المؤشرات الإنتاجية لمحصول الذرة الثامية في مصر خلال الفترة (2008- 2018)

\begin{tabular}{|c|c|c|c|c|c|c|}
\hline الرقم القياسي & (الإنتاج & الرقم القياسي & 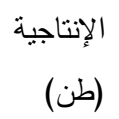 & الرقم القياسي & فدان) المساحة (الألف & السنوات \\
\hline 100.00 & 6.31 & 100.00 & 3.28 & 100.00 & 1860 & 2008 \\
\hline 104.60 & 6.6 & 102.44 & 3.36 & 106.32 & 1977.6 & 2009 \\
\hline 99.37 & 6.27 & 95.73 & 3.14 & 107.42 & 1998 & 2010 \\
\hline 93.19 & 5.88 & 102.13 & 3.35 & 94.52 & 1758 & 2011 \\
\hline 114.10 & 7.2 & 101.83 & 3.34 & 115.97 & 2157 & 2012 \\
\hline 112.52 & 7.1 & 101.22 & 3.32 & 115.00 & 2139 & 2013 \\
\hline 114.10 & 7.2 & 101.22 & 3.32 & 133.01 & 2474 & 2014 \\
\hline 111.73 & 7.05 & 95.12 & 3.12 & 140.54 & 2614 & 2015 \\
\hline 113.79 & 7.18 & 96.95 & 3.18 & 119.07 & 2214.66 & 2016 \\
\hline 121.39 & 7.66 & 99.70 & 3.27 & 123.64 & 2299.7 & 2017 \\
\hline 117.75 & 7.43 & 92.99 & 3.05 & 125.57 & 2335.6 & 2018 \\
\hline 109.32 & 6.90 & 99.03 & 3.25 & 116.50 & 2166.14 & المتوسط \\
\hline
\end{tabular}

المصدر: جمعت وحسبت من وزارة الزراعة واستصلاح الأراضي- قطاع الثئون الاقتصادية، نشرات الاقتصاد الزراعي، أعداد مختلفة.

كما أن النموذج المقدر للاتجاه الزمني العام للإنتاج الكلي لمحصول الذرة الثنامية الصيفى تأكد معنويته إحصائياً خلال فترة الدراسة، وان هذه المساحة تزيد سنوياً بمقدار 4.88 ألف فدان تمثل حوالى 70.7\% من المتوسط السنوي لفترة الدراسة. وبدراسة النموذج المقدر للاتجاه الزمني العام للمساحة المزروعة من محصول الذرة الثامية في مصر خلال فترة الدراسة كما هو وارد فى جدول (3) ، ينبين أنه يزداد بمعدل متزايد سنوياً بمقادير مؤكدة إحصائياً بلغت حوالي 57.69ألف فدان بمعدل زيادة بلغ نحو 2.7\% من من متوسط المساحة المزروعة للمحصول والتي بلغت حوالي 2166.14 ألف فدان خلال فترة الدراسة ، وبلغ معامل التحديد 0.55، أي أن 55\% من التغيرات في المساحة المزروعة نرجع لعامل الزمن. أما الإنتاجية الفدانية لمحصول الذرة الثامية في مصر خلال فترة الدراسة تتاقص بمقادير غير مؤكدة إحصائياً بلغت حوالي 017.0طن/فدان. بينما الإنتاج الكلي لمحصول الذرة الثامية خلال فترة الدراسة كما هو وارد في جدول (3)، تبين أن الإنتاج يتزايد سنوياً بمقادير مؤكدة إحصائياً بلغت حوالي 0.136 مليون طن فدان بمعدل زيادة بلغ نحو 1.96\% من منوسط الإنتاج الكلي لمحصول الذرة الثامية والتي بلغت حوالي 6.90 مليون طن خلال فترة الدراسة، وبلغ معامل التحديد 66.66، أي أن 66\% من التغيرات في المساحة المزروعة ترجع لعامل الزمن.

جدول رقم3. الاتجاه الزمني العام للمساحة المزروعة والإنتاجية والإنتاج الكلى لمحصول الذرة الثامية في مصر خلال الفترة (2008 - 2018).

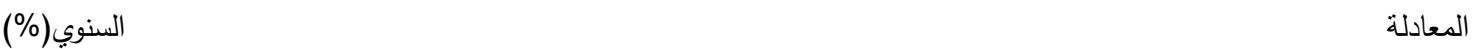

\begin{tabular}{|c|c|c|c|c|c|c|}
\hline 2.66 & 10.87 & 0.55 & 2166.14 & $\begin{array}{r}Y=1820.03+57.69 X \\
(3.296)^{* *}\end{array}$ & (الالف فداحة & 1 \\
\hline- & 3.43 & 0.28 & 3.25 & $\begin{array}{r}Y=33.35-0.017 X \\
(-1.85)\end{array}$ & $\begin{array}{r}\text { الإنتاجية الفدانية } \\
\text { (طن) }\end{array}$ & 2 \\
\hline 1.96 & 17.59 & 0.66 & 6.90 & $\begin{array}{r}Y=6.08+0.136 X \\
(4.19)^{* *}\end{array}$ & الإنتاج الكلي & 3 \\
\hline
\end{tabular}

المصدر: جمعت وحسبت من بيانات الجدول رقم (2) 
ثالثا: مؤثرات الكفاءة الاقتصادية لمصصول الذرة الثامية في مصر

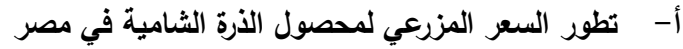

بدراسة بعض المؤشرات الاقتصادية لمحصول الذرة الثنامية تبين من الجدول (4) أن السعر المزرعي تزايد خلال الفترة (2008 -2018) من 198

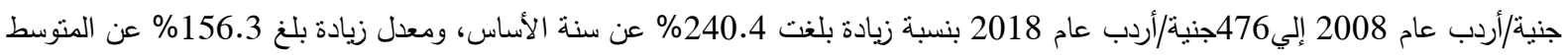
الذي قدر 309.45 جنية/اردب.

\section{ب- تطور التكاليف الكلية لمحصول الذرة الثامية في مصر}

يتضح من الجدول (4) أن النكاليف الكلية لمحصول الذرة الثامية تزايد خلال الفنزة (2008 -2018) من 2146 جنيه/فدان عام 2009 إلى

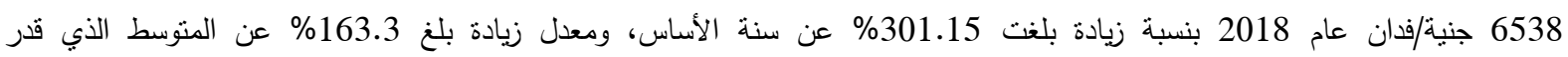
3544.45جنية/فدان.

\section{ت- تطور صافي العائد لمحصول الذرة الثامية في مصر}

تثير بيانات جدول (4) تذبذب صافي العائد بين حد أدنى قدره 1611جنية/فدان عام 2009، وحد أقصى قدره 3430 جنية/فدان عام 2010، وقد قدر متوسط صافي العائد بحوالي.4884.8 بنسبة زيادة بلغت 137.23 من سنة الأساس. وبدراسة النموذج المقدر للاتجاه الزمني العام للسعر المزرعي لمحصول الذرة الثنامية خلال فتزرة الدراسة كما هو وارد بجدول (5) ، يتبين أن السعر

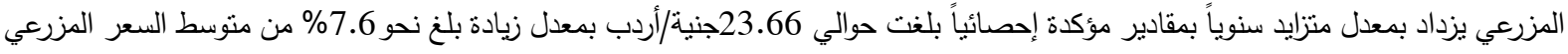

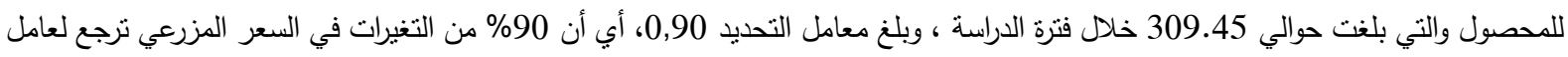
الزمن.

جدول رقم 4. المؤشرات الاقتصادية لمحصول الذرة الثنامية في مصر خلال الفترة (2008 - 2018).

\begin{tabular}{|c|c|c|c|c|c|c|}
\hline الرقم القياسي & (جنية/أردب العائد & الرقم القياسي & (جنية/أردب) التكاليف الكلية & الرقم القياسي & (جنية/أردب) المزرعي & السنوات \\
\hline 100.00 & 1753 & 100.00 & 2171 & 100.00 & 198 & 2008 \\
\hline 91.90 & 1611 & 98.85 & 2146 & 97.47 & 193 & 2009 \\
\hline 195.66 & 3430 & 106.86 & 2320 & 132.32 & 262 & 2010 \\
\hline 151.63 & 2658 & 128.83 & 2797 & 136.36 & 270 & 2011 \\
\hline 183.69 & 3220 & 135.88 & 2950 & 153.03 & 303 & 2012 \\
\hline 173.30 & 3038 & 152.69 & 3315 & 158.59 & 314 & 2013 \\
\hline 166.63 & 2921 & 159.01 & 3452 & 160.10 & 317 & 2014 \\
\hline 127.44 & 2234 & 173.19 & 3760 & 162.63 & 322 & 2015 \\
\hline 92.93 & 1629 & 189.45 & 4113 & 173.23 & 343 & 2016 \\
\hline 101.77 & 1784 & 249.98 & 5427 & 205.05 & 406 & 2017 \\
\hline 124.64 & 2185 & 301.15 & 6538 & 240.40 & 476 & 2018 \\
\hline 137.23 & 4884.8 & 163.26 & 3544.45 & 156.29 & 309.45 & المتوسط \\
\hline
\end{tabular}

المصدر: جمعت وحسبت من وزارة الزراعة واستصلاح الأراضي- قطاع الثئون الاقتصادية، نشرات الاقتصاد الزراعي، أعداد مختلفة.

أما التكاليف الكلية لمحصول الذرة الثامية تزداد بمعدل متزايد سنوباً بمقادير مؤكدة إحصائياً بلغت حوالي 388.78جنية/فدان بمعدل زبادة بلغ نحو 10.97 \% من متوسط التكاليف الكلية للمحصول والتي بلغت حوالي 3544.45جنية/فدان خلال فترة الدراسة، وبلغ معامل التحديد 0,87، أي أن 87\% من التغيرات في التكاليف الكلية ترجع لعامل الزمن. بينما قدر صافي العائد لمحصول الذرة الثامية بحوالي 33.62 جنيه/فدان بمعدل تغير متناقص. 
جدول رقم 5. الاتجاه الزمني العام للسعر المزرعي ، التكاليف الكلية، صافي العائد لمصصول الذرة الثامية في مصر خلال الفترة (2008 -

\begin{tabular}{|c|c|c|c|c|c|c|}
\hline السنوي(\% معدل التغير & $F$ & $\mathrm{R}^{2}$ & المتوسط & المعادلات & المتغير التابع & رقم \\
\hline 7.6 & $83.28^{* *}$ & 0.90 & 309.45 & $\begin{array}{r}Y=167.47+23.66 \mathrm{X} \\
(2.59)^{*}\end{array}$ & السعر المزرعي & 1 \\
\hline 10.97 & $58.39^{* * *}$ & 0.87 & 3544.45 & $\begin{array}{r}Y=1211.76+388.78 X \\
(7.64)^{* *}\end{array}$ & $\begin{aligned} \text { (التكاليف الكلية } \\
\text { (جنيه/فدان) }\end{aligned}$ & 2 \\
\hline- & 0.25 & 0.02 & 4884.8 & $\begin{array}{r}Y=2607.4-33.62 X \\
(-0.5)\end{array}$ & (جنية/ فداني العائد & 3 \\
\hline
\end{tabular}

المصدر: جمعت وحسبت من بيانات الجدول رقم (4)

رابعا: التقاير الإحصائي لدالات الإنتاج لمحصول الذرة الثامية وفقا لنظم الري بعينة الدارسة:

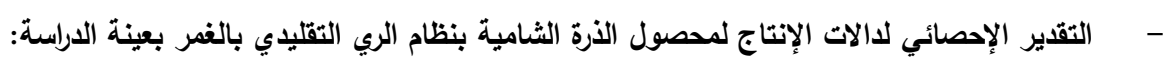

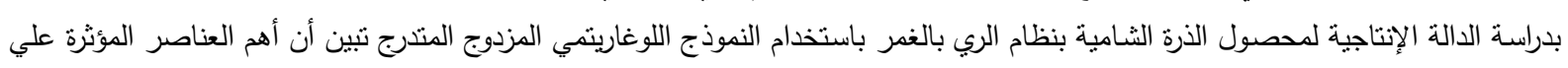

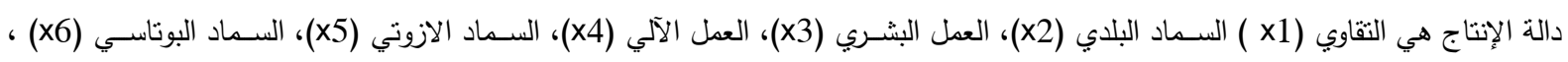

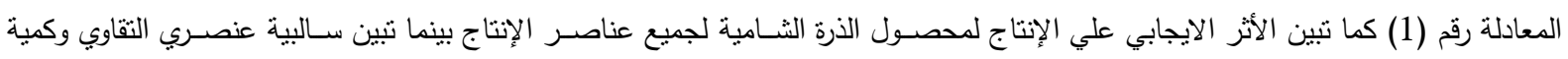

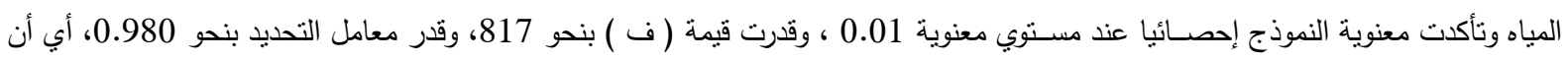

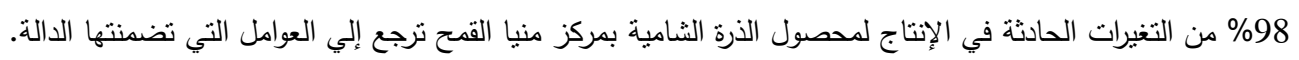

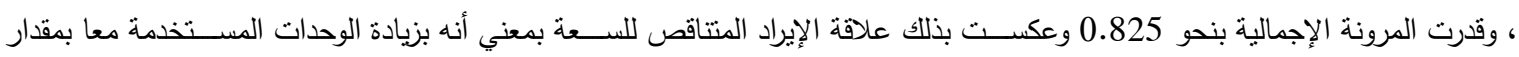

100\% فان الإنتاج الكلي سوف يزداد بمقدار 82.5\% - - التقلير الإحصائي لالات الإنتاج لمحصول الأنرة الثنامية بنظام الري بالتنقيط

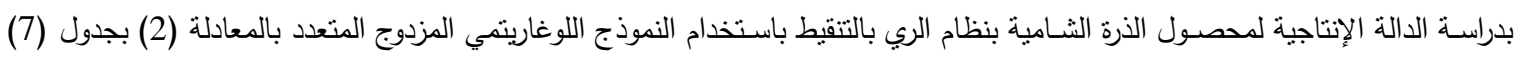

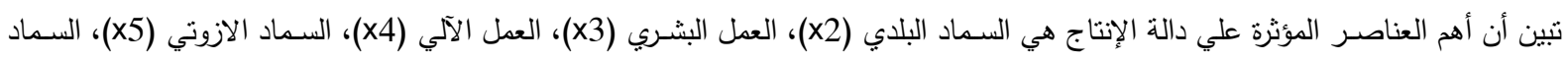

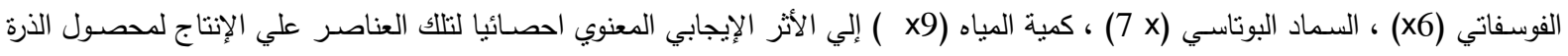

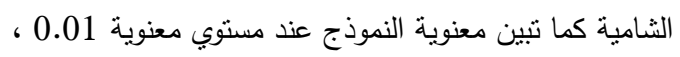

جدول6. التقدير الإحصائي لدالات الإنتاج لمحصول الذرة الثامية وفقا لنظم الري بعينة الدراسة

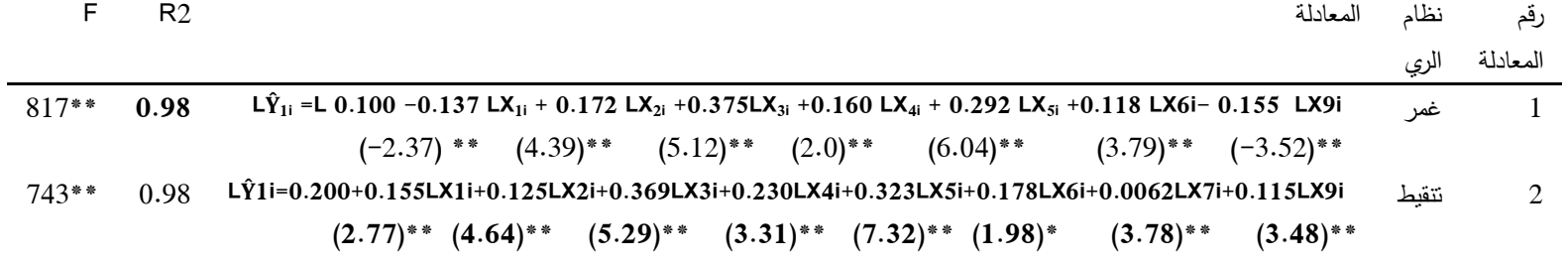

المصدر: جمعت وحسبت من استمارات استبيان عينة الدراسة.

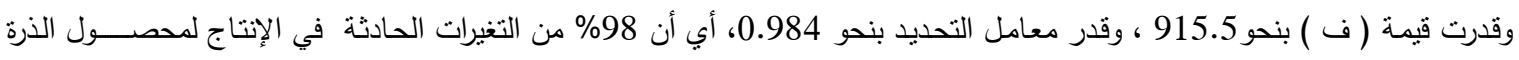

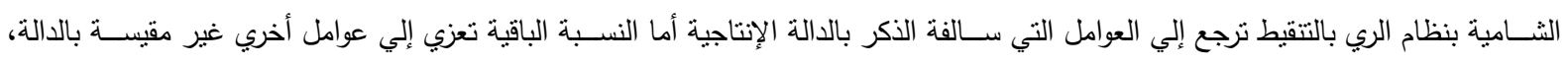

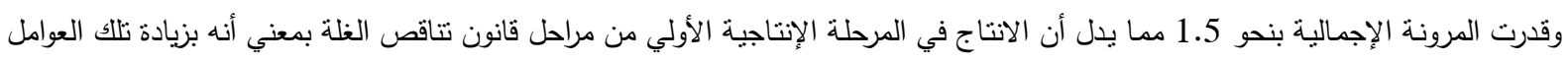

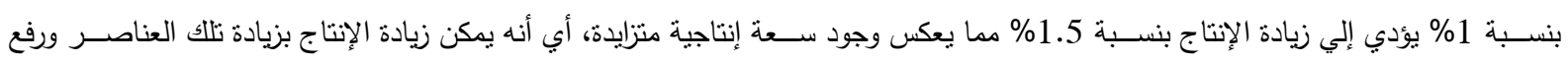
كفائتها الإنتاجية. 


\section{خامسا: الكفاءة الاقتصادية لمحصول الذرة الثامية وفقا لنظم الري بعينة الدراسة:}

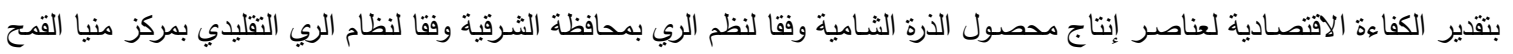

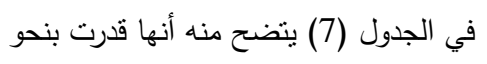

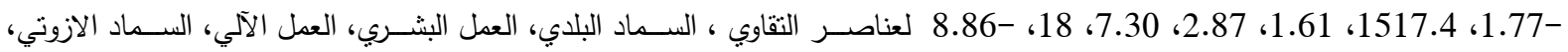

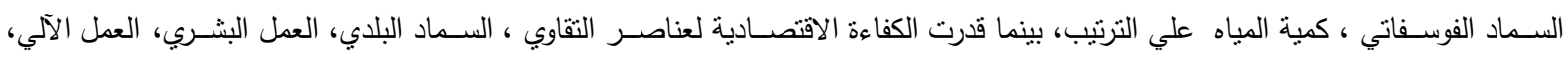

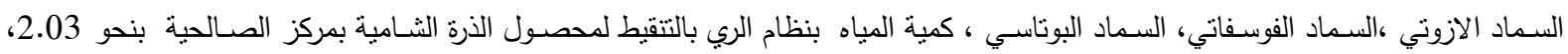

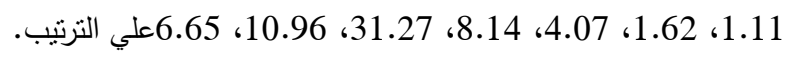

جدول رقم 7. الكفاءة الإنتاجية والاقتصادية لعناصر إنتاج محصول الذرة الثامية وفقا لنظم الري بمحافظة الثرقية بعينة الدراسة الميدانية للموسم

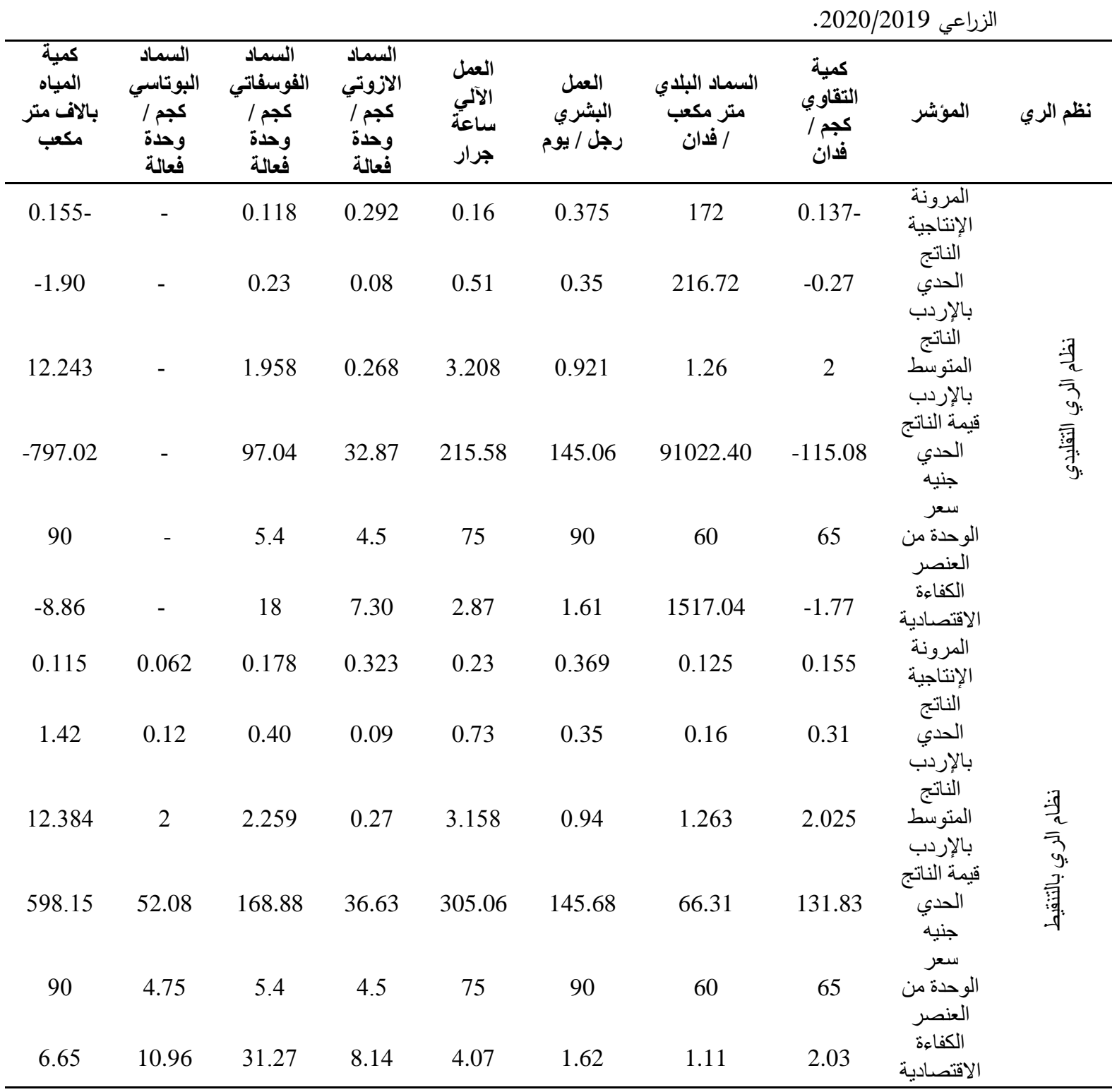

المصدر: جمعت وحسبت من بيانات استمارة الاستبيان بعينة الدراسة للموسم الزراعي (2020/2019).

أ- الناتج الحدي لعناصر إنتاج محصول الذرة الثامية:-

تم اثنقاق الناتج الحدي لعناصر إنتاج محصول الذرة الثـامية وفقا لنظم الري في محافظة الثرقية وفقا لنظام الري الثقليدي بمركز منيا

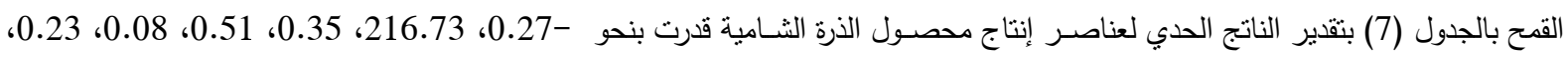
-1.90 لعناصر التقاوي ، السماد البلدي، العمل البثري، العمل الآلي، السماد الازوتي، السماد الفوسفاتي ، كمية المياه علي الترتيب ، بينما قدر 
الناتج الحدي لعناصـر التقاوي ، السـماد البلدي، العمل البثـري، العمل الآلي، السـماد الازوتي ،السـماد الفوسـفاتي، السـماد البوتاسـي ، كمية المياه بنظام الري بالتنقيط لمحصول الذرة الثامية بمركز الصالحية بنحو 0.31، 0.16، 0.35، 0.73، 0.09، 0.40،

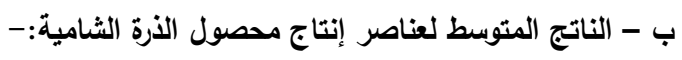
بتقدير الناتج المتوسط لعناصـر إنتاج محصـول الذرة الثـامية وفقا لنظام الري التقليدي بمركز منيا القمح بالجدول (7) يتضـح منه أنها قدرت

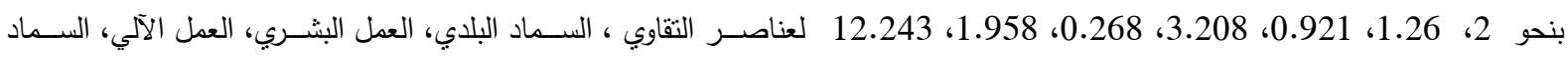

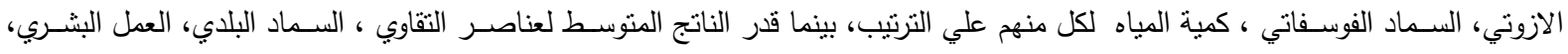
العمل الآلي، السماد الازوتي ،السماد الفوسفاتي، السماد البوتاسي ، كمية المياه بنظام الري بالتتقيط لمحصول الذرة الثامية بمركز الصالحية بنحو

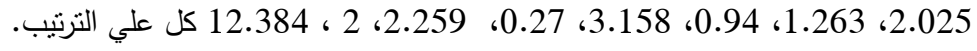

ج- قيمة الناتج الحدي لعناصر إنتاج محصول الذرة الثامية:بتقدير قيمة الناتج الحدي لعناصـر إنتاج محصـول الذرة الثـامية وفقا لنظام الري التقليدي بمركز منيا القمح بالجدول (7) يتضـح منه أنها قدرت

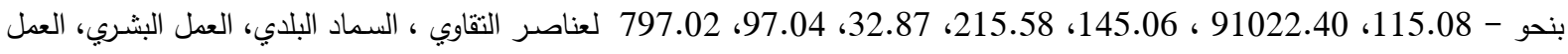

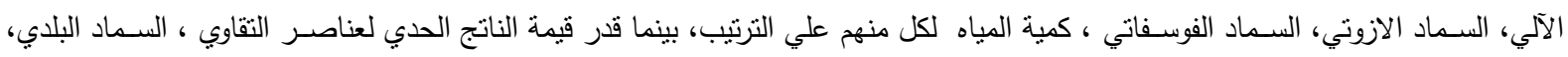

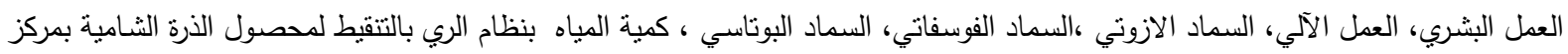
الصالحية بنحو 131.83، 66.31، 145.68، 36.63، 305.06، 168.88،

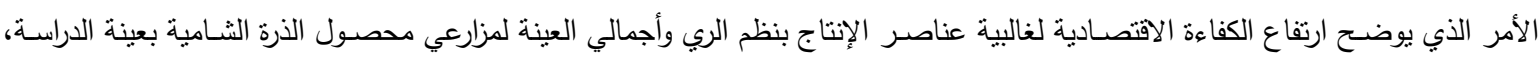

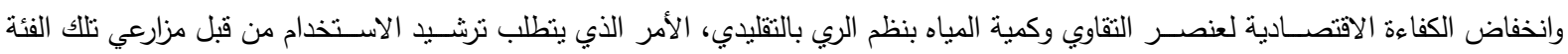

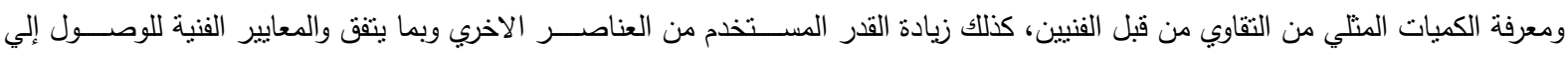
الكفاءة الاقتصادية القصوي. سادسا: معايير الكفاءة الإنتاجية والاقتصادية لمحصول الذرة الثامية وفقا لنظم الري بعينة الدراسة في محافظة الثرقية للموسم الزراعي 2020/2019

تشبير البيانات الواردة بالجدول (8) أن متوسط إنتاجية الفدان من محصول الذرة الثـامية وفقا لنظام الري بالغمر بعينة الدراسـة في محافظة

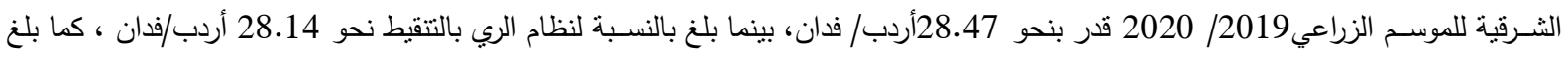

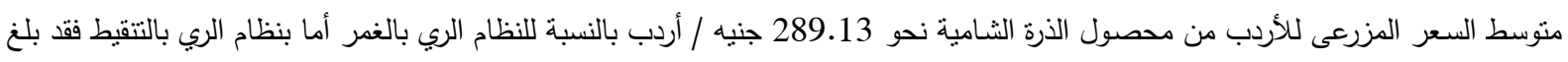

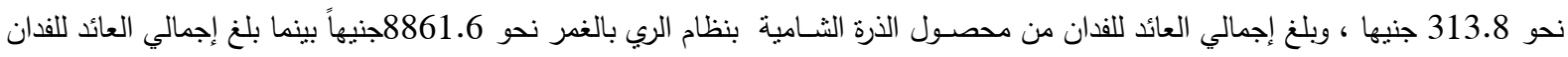

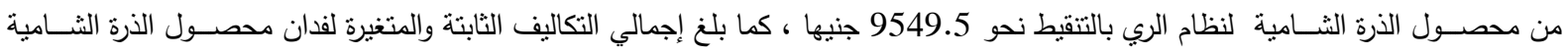

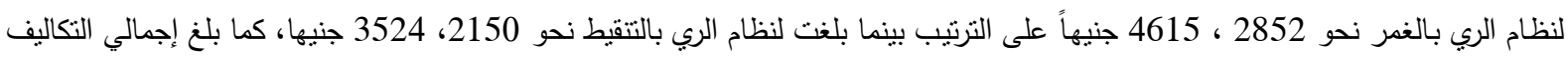

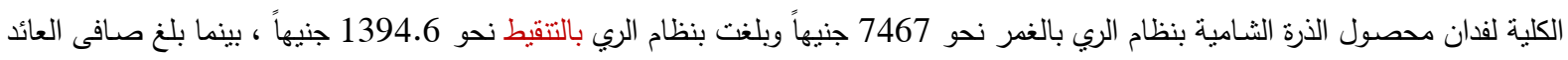

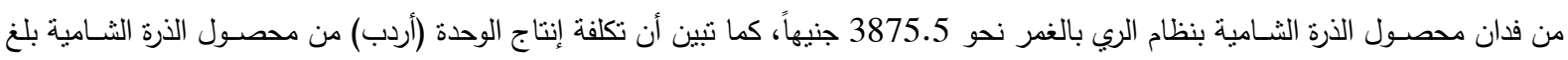

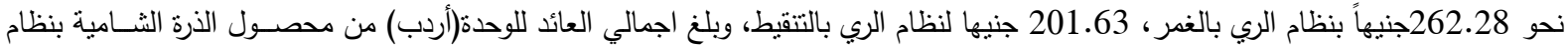

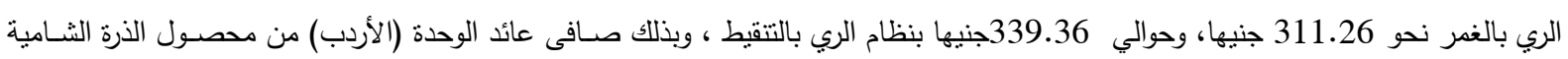
بنظام الري بالغمر نحو 49جنيهاً ، وبلغ نحو 339.36 جنيها لنظام الري بالتنقيط.

\section{-}

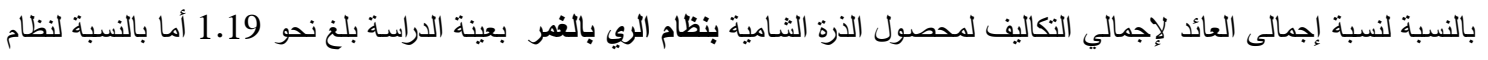

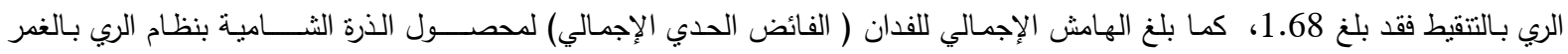
نحو 4246.6جنيها بينما بلغ بالنسبة لنظام الري بالتنقيط نحو 6025.5 جنيها أما بالنسبة لعائد الجنيه المستثمر لمحصول الذرة الثـامية بنظام

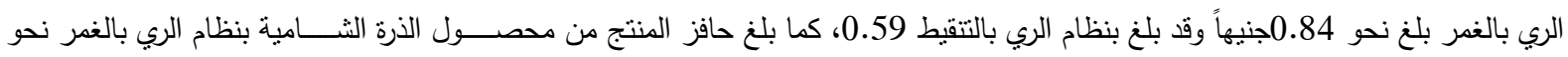

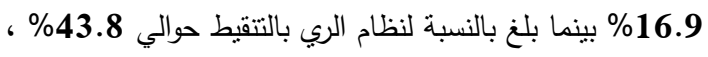


جدول8. أهم معايير الكفاءة الإنتاجية والاقتصادية لمحصول الذرة الثامية وفقا لنظم الري بعينة الدراسة في محافظة الثرقية للموسم الزراعي 2020/2019

\begin{tabular}{|c|c|c|}
\hline الري بالرش & الري بالغمر & 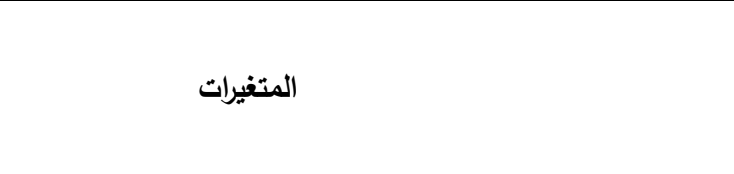 \\
\hline 1200 & 2550 & تكلفة العمل البشرى (بالجنيه) \\
\hline 1964 & 1710 & تكلفة العمل الألى (بالجنبه) \\
\hline 3164 & 4260 & إجمالى تكلفة العمل المزرعى (بالجنيه) \\
\hline 360 & 355 & إجمالى قيمة المستلزمات (بالجنيه) \\
\hline 3524 & 4615 & إجمالى التكاليف المتغيرة (بالجنيه) \\
\hline 2150 & 2852 & إجمالى التكاليف الثابتة (بالجنيه) \\
\hline 5674 & 7467 & إجمالى التكاليف الكلية (بالجنيه) (1) \\
\hline 28.14 & 28.47 & إنتاجية المحصول الرئيسي (بالاردب ) \\
\hline 6 & 7 & إنتاجية المحصول الثانوي (بالطن) \\
\hline 313.8 & 289.13 & متوسط سعر الاردب للمحصول الرئيسي (بالجنيه) \\
\hline 120 & 90 & متوسط سعر الحمل للمحصول الثانوي (بالجنبه) \\
\hline 8829.5 & 8231.6 & إجمالى العائد للمحصول الرئيسي (بالجنيه ) \\
\hline 720 & 630 & إجمالى العائد للمحصول الثانوي (بالجنيه ) \\
\hline 9549.5 & 8861.6 & إجمالى العائد للمحصول الكلي ( جنيه / فدان ) \\
\hline 3875.5 & 1394.6 & صافي العائد للمحصول (بالجنيه) \\
\hline 2.115 & 2.324 & كمية المياه بالالف /ק3 \\
\hline 201.63 & 262.28 & تكلفة إنتاج الوحدة للاردب (بالجنيه) \\
\hline 339.36 & 311.26 & اجمالي العائد للوحدة \\
\hline 137.7 & 49 & صافي العائد للأردب (بالجنيه) \\
\hline 1.68 & 1.19 & إجمالى العائد لإجمالي التكاليف \\
\hline 6025.5 & 4246.6 & الهامش الإجمالي للفدان( الفائض الحدي الإجمالي) \\
\hline 0.59 & 0.84 & عائد الجنيه المستثمر ع \\
\hline 43.8 & 16.9 & حافز المنتج \\
\hline 75.15 & 81.6 & كمية المياه اللازمة لإنتاج وحدة من النشاط الانتاجي م3 /الاردب \\
\hline 0.01 & 0.012 & أنتاجية الوحدة من المياه (اردب لكل م3) \\
\hline 4.5 & 3.8 & عائد الوحدة من المياه (جنيه/23) \\
\hline 1.8 & 0.6 & صافي عائد الوحدة من المياه (جنيه/ م3) \\
\hline 2.6 & 3.2 & تكلفة وحدة المياه للتكاليف الكلية ( جنية /23) \\
\hline
\end{tabular}

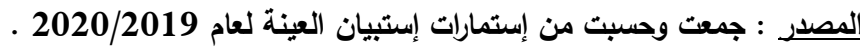

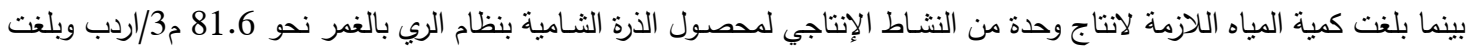

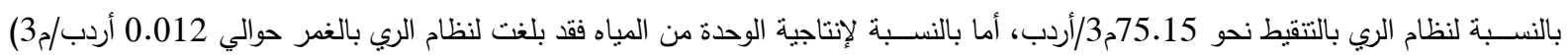

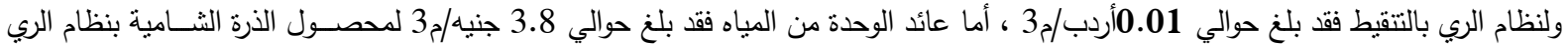

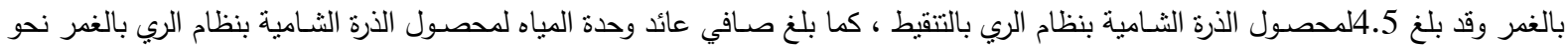

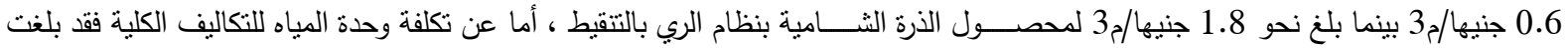

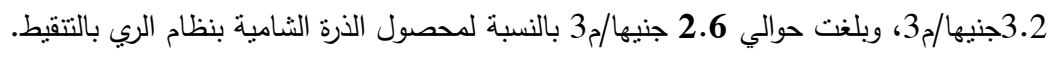




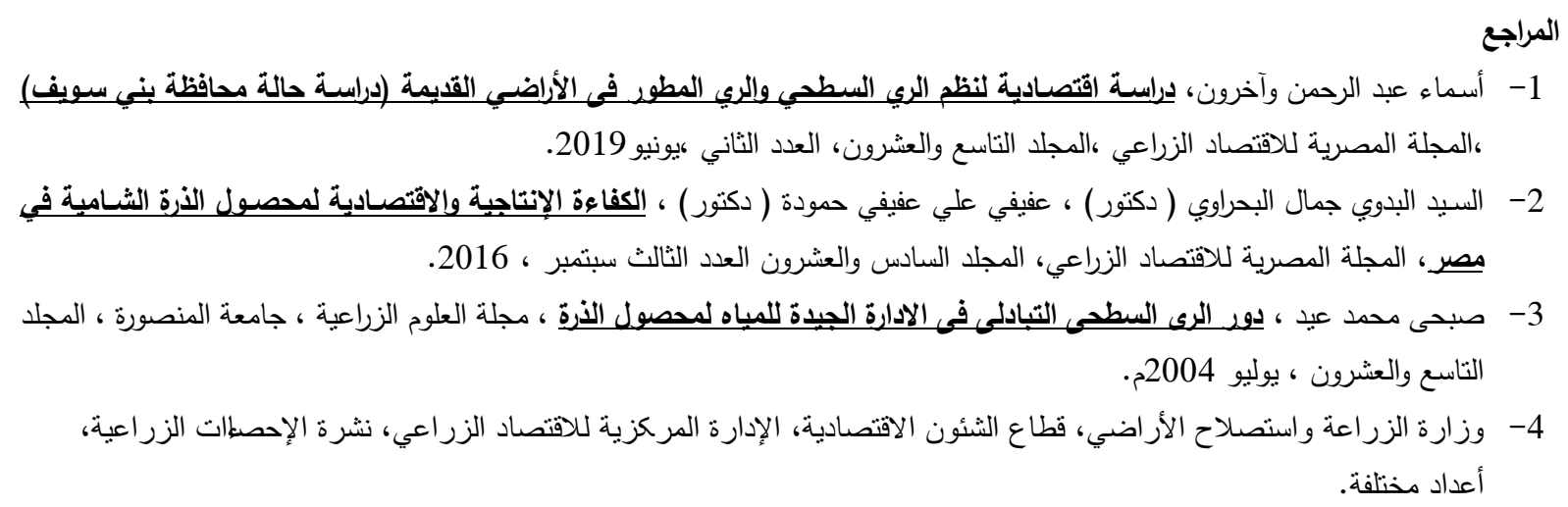

\title{
The economics of the maize crop according to the irrigation systems in Sharkia
} Governorate

\author{
Heba Hosney Mahmoud Pro.Dr Mohammed AbdEL-Naby DesoUkI \\ Agricultural Economics Research institute \\ Agriculural Research Center \\ - Prof. Dr Elsayed HassanMohamed Gado- Prof. Dr. MohamedSaid Amin EL - Sheshtawy \\ Faculty of Agriculture, \\ Banha University
}

\begin{abstract}
Summary
Maize is one of the main and important cereal crops in Egypt, due to the multiplicity of areas of its use, whether it is human food (human) and animal food (animal and poultry), and the newly reclaimed and cultivated lands form an important part of the state's plan for horizontal expansion and large areas of these lands can be cultivated. The study focused on identifying the current production status of the maize crop in the Sharkia governorate compared to the republic during the period (2008-2018) as it was estimated that the production of maize increased and the quantities imported from abroad which were used as fodder. The area cultivated from the maize crop across the Republic is about 2,166.14 thousand feddans during the period from (2008-2018), while the annual average of the cultivated area in Sharkia governorate is about 248.95 thousand feddans, representing the average cultivated area in the Sharkia governorate to its counterparts at the level of the Republic during the previous period about $11.61 \%$, And the average feddan productivity reached 3.25 tons / acre, 3.34 tons / acre at the level of the Republic and the Eastern Governorate respectively. As for the total production of the maize crop, the average production amounted to 6908.53 thousand tons, 852.07 thousand tons at the level of the Republic, and the Eastern Governorate, respectively, and the average total production of the Eastern Province represents about $12.38 \%$ for the Republic during the study period. By studying some economic indicators of the maize crop, it was found that the agricultural price of the maize crop during the study period increased at an annual increasing rate of about 23.66 pounds / ardeb, at an increase rate of about $7.6 \%$ of the average farm price of the crop, which amounted to about 309.45 during the study period, While the total costs increase at an annual increasing rate by about 388.78 pounds / acre, at an increase rate of about $10.97 \%$ of the average total costs, which were estimated at 3544.45 pounds / feddan during the study period, while the net yield of maize crop was estimated and took a decreasing rate of about 33.62 pounds / acre. With a change rate of about $-1.39 \%$. While the economic efficiency of the seed elements, municipal fertilizer, mechanical work, nitrogen fertilizer, potassium fertilizer, the amount of water according to the drip irrigation system for maize crops in Al Salhia center was estimated at 2.03, 1.11, 1.62, 4.07, 8.14, 10.96, 31.27, 31.27, 6.65. Accordingly, the total cost per acre of maize crop with flood irrigation system reached about 7467 pounds, and the drip irrigation system reached 1394.6 pounds. While the net yield of the acre of the maize crop in the flood irrigation system amounted to about 3875.5 pounds, and it was also found that the cost of producing the unit (ardab) of the maize crop amounted to about 262.28 pounds in the flood irrigation system, 201.63 pounds for the drip irrigation system, and the total return per unit (Ardab) Of the maize crop in the flood irrigation system, about 311.26 pounds, and about 339.36 pounds in the drip irrigation system. The unit return from water was about 3.8 pounds / $\mathrm{m} 3$ for the maize crop in the flood irrigation system, and it reached 4.5 for the maize crop in the drip irrigation system. The water for maize crop by flood irrigation system was about 0.6 pounds / $\mathrm{m} 3$, while it was about 1.8 pounds $/ \mathrm{m} 3$ for maize crop by drip irrigation system. As for the cost of the water unit for the total costs, it reached 3.2 pounds $/ \mathrm{m} 3$, and it reached about 2.6 pounds / $\mathrm{m} 3$ for the maize crop. With flood irrigation system, drip irrigation respectively
\end{abstract}

